\title{
A política da reforma do Estado: um exame de abordagens teóricas
}

Em toda a Europa Oriental e América Latina, um dos desafios centrais para a consolidação da reforma da democracia e do mercado foi a criação de burocracias estatais capazes de implementar políticas econômicas, oferecer serviços sociais e manter a ordem pública. Durante parte dos anos 80, a importância desse desafio foi obscurecida por severas crises fiscais, que levaram à redução das atividades convencionalmente atribuídas ao setor público. De maneira discutível, tais reformas pavimentaram o caminho do estabelecimento de um setor público mais capaz, por meio da redução dos desequilíbrios fiscais e estabelecimento de condições macroeconômicas mais sustentáveis. Mas os responsáveis pela reforma da economia na última década deram pouca atenção aos temas relativos à reestruturação administrativa, e pouco fizeram para frear a deterioração dos recursos humanos dentro do setor público.

Em meados da década de 90, a questão da reconstrução das capacidades estatais avançou com certa dificuldade para a arena pública. Nas esferas financeiras internacionais, a atenção crescente a esse tema foi, em parte, motivada pela preocupação em "congelar" as reformas fiscais e de mercado da década anterior, e em parte pela preocupação com a transição para políticas sociais e reguladoras que exigiam capacidades administrativas ainda maiores. Enquanto seria exagerado falar de um "consenso de Washington”, comparável àquele que se estabeleceu em relação às políticas de reforma nos anos 80, a agenda da reforma do Estado, que tem sido atualmente debatida na América Latina e Europa Oriental, foi fortemente influenciada por, no mínimo, quatro grandes temas desenvolvidos pelo Banco Mundial e outras instituições de financiamento internacional:
Professor of political science, Rutgers University, New Brusnwiek, New Jersey - USA.

Traduzido por Christina Ervilha e Vanessa Silveira 
1. A centralização e o isolamento político do controle sobre a política macroeconômica, particularmente das despesas e decisões monetárias. Nesse contexto, tem sido especialmente enfatizada a delegação de autoridade sobre a política monetária para bancos centrais que não estejam diretamente sujeitos à autoridade constante do Executivo eleito ou do Legislativo.

2. A descentralização e/ou privatização da burocracia encarregada da prestação de serviços sociais — pressupondo que as autoridades locais fossem mais sensíveis às demandas de seus eleitores, e que a competição entre os fornecedores aumentasse a eficiência dos serviços.

3. A delegação de funções reguladoras a agências independentes, encarregadas de supervisionar os prestadores de serviços e de lidar com externalidades associadas à privatização, liberalização do mercado e outras reformas especificamente voltadas para o mercado.

4. A criação de quadros mais capacitados de servidores públicos. Eles seriam recrutados de acordo com critérios meritocráticos, teriam autoridade considerável sobre os procedimentos operacionais, e seriam avaliados em termos de padrões de desempenho.

Em que condições pode-se esperar que tais reformas institucionais sejam implementadas, e até que ponto elas tendem a alcançar os resultados desejados? Comecemos pelo pressuposto de que a reforma do Estado não é simplesmente uma questão de congregar a "vontade política" necessária para a implementação de fórmulas institucionais "corretas". Mais que as reformas na política econômica, os esforços para modificar a estrutura institucional onde se elabora e implementa a política serão afetados pelo conflito e negociação entre grupos de interesses domésticos e internacionais, políticos e burocratas, muitos com altos interesses no status quo institucional. Assim, apesar do enorme clamor público, identificado em muitos países, por mais honestidade, transparência e eqüidade dentro do setor público, nações de ambas regiões são caracterizadas pela persistência daquilo que Guillermo O'Donnell chamou brown areas, nas quais as agências estatais têm pouca autonomia em relação a interesses específicos, e oferecem poucos dos serviços básicos esperados de organizações estatais. ${ }^{1}$

A compreensão dos desdobramentos da organização estatal e também das políticas de reforma requer a identificação de atores de relevância no processo político, a especificação de suas preferências e de seus recursos políticos, e uma análise da maneira pela qual suas decisões são dificultadas pelas estruturas sociais e políticas vigentes. Neste documento, investigo como três diferentes perspectivas teóricas lidaram com estas questões: o institucionalismo da economia política (IEP), o institucionalismo da escolha racional (IER) e o institucionalismo da sociologia ou sociologia institucional (IS). Estas perspectivas podem ser complementares ou excludentes, mas cada uma oferece explicações diferentes sobre atores, preferências e dificuldades. 
Abordagens de IEP explicam os resultados políticos e a mudança institucional, analisando as relações entre grupos de interesse econômico e suas inserções nos mercados de comércio global e de capital. Um ponto-chave que emerge dessa abordagem é a extensão na qual os líderes políticos nacionais têm suas escolhas, sobre a reforma do Estado, limitadas pela globalização desses mercados, e pelo fortalecimento dos grupos econômicos de apoio atentos ao mercado internacional.

As perspectivas do IER tendem a enfatizar o "lado da oferta" da reforma estatal. Uma premissa central dessa abordagem é que a (re)organização burocrática reflete as preferências de competidores políticos, cujos objetivos básicos são conseguir ou manter seu posto. As reações às demandas pela reforma estatal dependeriam de como tais atores calculassem que a reforma afetaria sua capacidade de competir com políticos rivais. Isso, por sua vez, dependeria de como os sistemas eleitorais e constitucionais estruturassem as regras da competição e a importância relativa de eleitorados diferentes.

Finalmente, o IS analisa a matriz maior de instituições e normas sociais nas quais o comportamento econômico e burocrático está inserido. Ao contrário do IER ou da abordagem IEP, as teorias sociológicas tomam como problema a identidade dos atores e a maneira pela qual suas preferências são formadas. Elas também abrem caminho para uma maior investigação dos atores que não estão inteiramente situados em instituições de mercado ou do Estado.

Se adotarmos uma visão de longo prazo, cada uma dessas abordagens deverá situar-se dentro de análises mais "fundamentais", que considerem os Estados como produtos de guerras, lutas de classes e revoluções. Na Europa Ocidental, os incentivos à construção de forças armadas permanentes e burocracias civis eficazes brotaram, em grande parte, de contínuas disputas militares e lutas de classes domésticas, ao passo que a capacidade de responder a tais desafios dependia dos recursos materiais e humanos dos quais dispunham os governantes e seus eleitores mais poderosos. $^{2}$

Esses acontecimentos, por sua vez, dificultaram as oportunidades de emergência de Estados fortes em outras partes do Globo. Desde o século XVI, a limitação da população e de capital tornou as sociedades da Europa Oriental vulneráveis à ação predatória de seus vizinhos. Da mesma forma, a fraqueza pós-colonial dos Estados latino-americanos está, sem dúvida, relacionada à sua dependência dos patrões todo-poderosos durante os séculos XIX e XX.

Enquanto a relevância desse amplo contexto histórico deva ser devidamente observada, é difícil demonstrar sistematicamente a conexão entre as raízes "profundamente estruturais" da formação do estado e os temas mais urgentes da reforma estatal, tal qual encontra-se hoje na agenda 
das sociedades ex-comunistas e em desenvolvimento. Afinal, já faz bastante tempo que as disputas internacionais políticas e econômicas começaram a remodelar tais sociedades, nos séculos XVI e XVII, e uma tentativa de traçar os elos causais que nos trouxeram ao presente iria levar-nos muito além do escopo do presente estudo.

As abordagens aqui consideradas têm a vantagem de enfocar processos políticos mais próximos dos resultados que queremos analisar. Assim eles serão, no mínimo, suplementos necessários a explanações macrohistóricas. Pesquisas bastante completas das grandes obras literárias que compõem cada uma dessas abordagens foram realizadas por outros. ${ }^{3}$ Meu objetivo neste estudo é explicar algumas das hipóteses sobre reforma do Estado contidas em cada perspectiva, observando as vantagens e limitações de cada abordagem, e finalmente fornecer uma avaliação preliminar de sua relevância para a pesquisa empírica na América Latina e Europa Oriental.

\section{Abordagens do institucionalismo da economia política (IEP)}

Durante os anos 80 e 90, os primeiros impulsos pelas reformas da política e do Estado vieram de atores da comunidade financeira e política internacional e seus aliados nas economias políticas domésticas. Por essa razão, as abordagens de economia política fornecem um ponto de entrada promissor para que se analise como devem transformar-se os estados contemporâneos. Nem todos os estudantes de economia política concordam, obviamente, com a predominância de "fatores internacionais"; de fato, esse é um tema de debate considerável. Mas muitos observam de forma sistemática os atores que desempenham papéis no comércio internacional e nos mercados de capital, como também os grupos domésticos de interesse econômico que se dispõem a ganhar ou perder ao participarem desses mercados.

Como sugerido na introdução, as análises contemporâneas têm-se prendido às implicações da integração dramática desses mercados durante as décadas passadas. Num ensaio recente, Ronald Rogowski e Jeffry Frieden analisam as conseqüências do mercado internacional em expansão. ${ }^{4}$ À medida que caem os custos de transação, afirmam eles, os governos nacionais enfrentam dois tipos de pressão por reformas comerciais: um, dos grupos que obtêm benefícios distributivos das reformas, e um segundo, dos ganhos políticos derivados dos efeitos agregados da reforma comercial na renda nacional. A facilidade do comércio aumenta o potencial de retorno aos grupos voltados para o mercado internacional, encorajando assim a mobilização de apoio à liberalização. Ao mesmo 
tempo, as perspectivas de ganhos comerciais agregados crescentes aumentam as chances de que empresários políticos dêem início a mudanças nas políticas que atrairão o apoio de amplos setores da população.

O fato de que a globalização dos mercados de capital tenha tido implicações distributivas e agregadas similares é discutível. O crescimento do volume e a volatilidade dos fluxos financeiros internacionais forneceu aos bancos, administradores de carteiras e credores multinacionais um poderoso impulso sobre as políticas de taxas de juros e câmbio. Dada a rapidez com que as transferências de capital ocorrem, políticas macroeconômicas sem credibilidade podem ter conseqüências sobre a taxa de câmbio e a inflação doméstica que serão percebidas em toda a economia. A crescente importância dos fluxos financeiros externos na sustentação da balança de pagamentos representou, assim, um forte incentivo para que os políticos mantivessem políticas macroeconômicas estáveis.

As mudanças nas instituições macroeconômicas de tomada de decisão também poderão ser afetadas por tais incentivos. Obviamente, pode ser mais fácil alterar práticas e metas (políticas) governamentais que mudar as regras do processo de elaboração das políticas. Ainda assim, é bastante possível que os responsáveis pelas reformas busquem mudanças institucionais que visem o aumento da eficácia e da credibilidade de suas reformas na política macroeconômica. Por essa razão, os argumentos esboçados acima sugerem várias hipóteses relevantes para as políticas de reforma do Estado, tanto na América Latina quanto na Europa Oriental.

A primeira delas é que o aumento do comércio e da competição por capital encorajaria a convergência das estruturas do Estado em direção a modelos institucionais que ampliem a competitividade e sejam considerados aceitáveis em sociedades capitalistas avançadas. Essa é, por exemplo, a tese central do recente trabalho de Sylvia Maxfield sobre as fontes de influência do Banco Central. ${ }^{5}$ Ela afirma que a tendência mundial em favor da independência do Banco Central reflete, em parte, o impacto fortalecido dos fluxos de capital internacional nas finanças públicas e na estabilidade política. Seguindo a mesmo lógica, é possível afirmar, a exemplo de Frieden e Rogowski, que empresários políticos, tentando capitalizar seu ganhos agregados resultantes da liberalização do comércio, também queiram reduzir o acesso institucional aos juros distributivos, buscando isenções especiais. Isso exigiria a criação de estruturas decisórias de nível macroeconômico mais centralizadas, e o crescimento das bases eleitorais territoriais das autoridades eleitas. ${ }^{6}$

Ao passo que encoraja a centralização do controle dos instrumentos básicos de política macroeconômica, a globalização também deve aumentar o papel desempenhado pelos governos locais e regionais na prestação de serviços sociais e outros bens públicos. A hipótese básica é 
que as transações internacionais das autoridades locais, assim como de firmas com sedes regionais e outros atores, deverão tornar-se menos dependentes da mediação dos governos centrais. Instituições financeiras internacionais, tais como o Banco Mundial, têm reforçado tais tendências, enfatizando a eficiência potencial e os ganhos eqüitativos que podem derivar da descentralização da autoridade governamental.

Uma terceira hipótese sugerida por abordagens do IEP é a de que, de um país para outro, as variações de timing e extensão da reforma do Estado acompanharão a natureza das relações entre as economias doméstica e internacional. As tendências nacionais em favor da "agenda neoliberal" da reforma do Estado seriam mais fortes em países com setores bancário e exportador relativamente poderosos; aqueles mais fortemente ligados aos mercados dos EUA ou Europa; e/ou mais dependentes dos fluxos de capital internacional para financiar suas balanças de pagamentos. Os impulsos seriam mais fracos em países com mercados domésticos maiores e/ou com perspectivas mais limitadas de integração em blocos comerciais globais.

Finalmente, abordagens da economia política deixam implícita a importância relativa das pressões "do lado da demanda" no processo de reforma do Estado. Atores e instituições políticas podem desempenhar um papel importante na resolução de problemas de ação coletiva: de fato, a iniciativa da reforma das políticas macroeconômicas e das correspondentes mudanças institucionais partiu principalmente dos chefes de governo e de seus altos assessores financeiros, cujas grandes bases eleitorais têm o maior interesse no desempenho econômico agregado. Mas os atores políticos são vistos principalmente como intermediadores (brokers) ou empresários, cujo poder depende, em princípio, de sua capacidade de recorrer aos interesses econômicos de base para buscar apoio à reforma política e às mudanças nas instituições do Estado.

Que utilidade terão essas hipóteses para a compreensão das políticas da reforma do Estado na Europa Oriental e América Latina? Uma rápida investigação dos dados disponíveis sobre a reforma do Banco Central aponta para uma gama de padrões empíricos consistentes com esses argumentos. Primeiro, como sugerido, a tendência contemporânea em favor da independência formal do Banco Central apóia, de certa forma, a hipótese da convergência. Entre 1989 e 1993 - um período de rápida aceleração no investimento em "mercados emergentes" - Maxfield observa 23 instâncias de autoridade do Banco Central de jure, quase o dobro do número total registrado durante os 30 anos precedentes. Dentre as 23 reformas, onze ocorreram na América Latina (Argentina, Chile, Colômbia, México e Venezuela) e Europa Oriental (Bulgária, Eslováquia, Hungria, Polônia, Romênia e República Tcheca). ${ }^{7}$ 
As hipóteses do lado da demanda esboçadas acima também receberam, no mínimo, um apoio indireto das reformas que foram instituídas em tamanha variedade de sistemas políticos. Entre os países que realizaram reformas, incluíam-se tanto regimes parlamentaristas quanto presidencialistas, constituições centrais e federais, sistemas de partidos políticos fragmentados e aqueles relativamente consolidados. Como já se previa, essas mudanças tendiam a demorar-se na Rússia e no Brasil. Ambos são nações de tamanho continental, com mercados domésticos enormes e atores importantes, que preferem continuar a garantir sua porção da renda nacional por meio do controle administrativo, apesar dos custos substanciais que podem ocorrer durante períodos de instabilidade macroeconômica.

Uma evidência mais direta da hipótese do lado da demanda, finalmente, encontra-se em estudos estatísticos que comparam diversos países, mostrando que a independência do Banco Central está ligada mais diretamente à força dos sistemas bancário e financeiro dentro das economias nacionais, e menos às variações dos sistemas partidários e à estabilidade do regime. ${ }^{8}$

Por outro lado, ao passo que essa evidência comprova a utilidade potencial das abordagens como ponto de partida para a análise da reforma do Estado, há razões para duvidar que as versões das hipóteses anteriores possam ser generalizadas para além da reforma dos bancos centrais, ministérios da Fazenda, ou outras instituições macroeconômicas que tinham o privilégio de ocupar-se com a estabilização e a reforma comercial que dominavam a agenda política, dos anos 80 até o início da década de 90.

Em primeiro lugar, as dificuldades administrativas para a criação ou fortalecimento de agências macroeconômicas de elite são geralmente menos severas que as enfrentadas para reformar os enormes segmentos prestadores de serviço do aparato estatal. Iniciativas simpáticas à reforma dos estatutos de um banco central podem basear-se em modelos internacionais relativamente bem definidos. As exigências orçamentárias e de pessoal dos bancos centrais e ministérios econômicos também podem ser mais limitadas que as das grandes agências "de linha". Além disso, a reforma das agências macroeconômicas de elite pode ser realizada sem diminuir significativamente as oportunidades de apadrinhamento político em outras partes do aparato estatal. Este foi o modelo adotado, por exemplo, pela Bolívia depois de 1985, ou pelo México nos anos 80 e 90.

Finalmente, os mercados financeiros têm interesses mais limitados nas áreas fora do domínio da gestão macroeconômica; suas preocupações básicas referem-se às instituições que lidam com taxas de câmbio, balança de pagamentos e políticas monetárias. Observa-se que isso não impede o Banco Mundial e outros segmentos da comunidade política internacional de abrir debates sobre outros aspectos da reforma estatal, incluindo a 
descentralização dos serviços sociais, reforma do papel regulador, assistência social, etc. No entanto, além de ser essa uma agenda de reforma consideravelmente ampla, existe ainda muita incerteza sobre como determinadas decisões institucionais podem afetar a implementação da política.

Tal incerteza dá aos políticos muito espaço para responder aos interesses de clientelas domésticas particulares. De fato, na América Latina, tanto a extensão quanto o ritmo das reformas descentralizadoras foram altamente desiguais e influenciados pelos políticos domésticos. Em alguns países — o Chile é o exemplo mais claro — as metas de eficiência enfatizadas pelas instituições financeiras internacionais ocupavam um papel importante no caminho da descentralização. ${ }^{9}$ Já em outros países, como Brasil, Colômbia, Bolívia e Venezuela, o fortalecimento dos governos locais foi motivado por uma série de outros fatores: reações democráticas contra governos militares centralizadores; esforços presidenciais para reduzir o poder das elites corporativistas nacionais; preocupação em integrar grupos de base no sistema político. Ministérios da Fazenda e outras autoridades econômicas foram muitas vezes excluídos do grupo dirigente que conduziu as reformas, e foram freqüentemente contrários a muitas das provisões relativas à eficiência. ${ }^{10}$

Finalmente, no campo das instituições macroeconômicas, é importante não exagerar na arrancada das forças internacionais em defesa de uma maior centralização institucional. Mesmo considerando sua autoridade formal, é impossível que os bancos centrais e ministérios econômicos funcionem de forma eficiente se não puderem forçar as agências públicas a cumprirem seu papel de accountability com respeito ao fluxo de despesas e receitas da burocracia estatal. Como as experiências russo-soviéticas demonstraram de modo bastante vívido conduzir os vazamentos ilegais regionais e locais - , para tais fluxos de capital, pode ser o principal desafio das autoridades centrais. ${ }^{11}$ De modo mais amplo, a captação de receitas envolve sistemas bastante complexos de acompanhamento e cumprimento aparentemente voluntários, mas que podem enfraquecer a capacidade administrativa e política até mesmo da burocracia estatal mais avançada. ${ }^{12}$

Com relação especificamente ao tema dos bancos centrais, é crucial distinguir-se as reformas que aumentam a independência estatutária das instituições monetárias da real capacidade das autoridades monetárias de tomarem decisões independentes. Dados quantitativos analisados por Cuckierman, Webb e Neyapti indicam que a independência de jure do Banco Central não está diretamente relacionada ao mandato das autoridades monetárias, e é um indicador pobre da estabilidade monetária em países em desenvolvimento. ${ }^{13}$

Tais crenças generalizadas sobre a estrutura e o papel dessas instituições vão exigir um novo exame, dentro do contexto da crise do peso 
mexicano de 1994/1995; naquele caso, visivelmente, o Banco Central independente não foi suficiente para prevenir uma explosão. Essa experiência não desacredita a proposta de que uma certa forma de centralização e isolamento seja importante para superar os problemas de coordenação associados à estabilização e liberalização do comércio, mas encoraja a reabertura da discussão sobre a forma de alcançá-la, e até que ponto ela pode ser coordenada com outros aspectos da reforma estatal. ${ }^{14}$

\section{O institucionalismo na perspectiva da escolha racional (IER)}

A abordagem IER considera os políticos como, basicamente, "provedores" de políticas públicas e dos meios administrativos para implementálas. Outros atores, certamente, estão incluídos no domínio dessa abordagem, incluindo os atores econômicos discutidos na seção anterior; é certo que muitos dos conceitos-chave do IER advêm da análise do agenteprincipal e dos problemas dos custos de transação nas hierarquias econômicas. No entanto, cientistas políticos que trabalham nessa abordagem concentraram-se geralmente nas escolhas políticas estratégicas dos líderes partidários, legisladores e chefes de governo eleitos. Como sugerido na introdução, a premissa básica é de que o comportamento desses atores, incluindo suas reações à demanda de suas bases eleitorais pela reforma, dependerá de como as regras do jogo político estruturam a competição que eles irão enfrentar com outros políticos.

Nas décadas anteriores, a abordagem IER foi aplicada empiricamente, principalmente nas estruturas eleitorais e representativas dos Estados Unidos, em particular o Congresso americano. ${ }^{15}$ No entanto, com a disseminação das políticas eleitorais na América Latina e Europa Oriental, é possível que muitos dos instrumentos conceituais e proposições desenvolvidos no contexto institucional americano sejam adaptáveis para uma análise dos países dessas regiões. Como irei sugerir abaixo, é possível questionar a utilidade de imputar-se objetivos de mera busca de poder aos políticos de carreira eleitoral — uma conclusão usual da abordagem IER. No entanto, pode-se muito bem esperar que os políticos que aspirem a um mandato eleitoral atribuam importância crescente aos assuntos relacionados ao recrutamento, orçamento e mandato de agências governamentais.

Barbara Geddes afirmou que ao confrontarem-se com a reforma estatal, os políticos precisam contrabalançar a importância de maximizar suas chances pessoais de sobrevivência política com as metas coletivas que eles devem perseguir, ao agir como membros de um partido ou de uma "classe política". ${ }^{16}$ Devido ao seu alto interesse na sobrevivência do sistema eleitoral, presume-se que a "classe política" como um todo deseje 
apoiar a construção de burocracias públicas que ofereçam vários bens coletivos. Como membros de partidos, os políticos também podem querer encorajar a indicação de agentes burocráticos, com base na linha meritocrática, para implementar programas em prol de grandes blocos de eleitores. Por outro lado, a sobrevivência política dos indivíduos políticos deverá depender de suas bases eleitorais, construídas com a ajuda de apadrinhamento e do controle discricionário da distribuição dos recursos públicos. Este é um forte incentivo para que eles se oponham à "racionalização" burocrática. Os papéis institucionais e a distribuição de recursos políticos afetarão o tipo de escolhas que os atores farão com relação a esses objetivos. Pode-se esperar que chefes de Estado e líderes de grandes partidos políticos queiram contornar as ações coletivas contrárias à reforma, visto que elas deverão buscar o apoio de suas bases eleitorais em todo o país. Como Geddes sugere, no entanto, a tendência de perseguir tais metas será afetada pelos horizontes de tempo dos atores e pelo controle que estes tenham sobre suas próprias coalizões políticas. Líderes políticos ameaçados por golpes militares têm menos probabilidade de abrir mão do recurso do apadrinhamento político do que aqueles que podem colher as recompensas de um programa eficaz de desenvolvimento a longo prazo. As iniciativas de reforma também são menos prováveis em sistemas onde a fragmentação partidária ou a indisciplina aumentem a vulnerabilidade do Executivo às demandas de parceiros de sua coalizão ou de rivais em seus próprios partidos. ${ }^{17}$

As escolhas dos legisladores também refletirão a forma como os sistemas partidários e as estruturas legais afetam suas chances de reeleição. Em um estudo recente, Stephan Haggard resumiu uma série de fatores que podem levá-los a aceitar a reforma burocrática. ${ }^{18}$

a) A relativa importância dos apelos programáticos na estruturação do apoio eleitoral: a importância do apadrinhamento político tende a declinar em sistemas onde eleitores avaliam os candidatos de acordo com sua associação a um programa ou partido particular. Os políticos, por sua vez, são, cada vez mais, incentivados a cooperar com o estabelecimento de agências que tenham a capacidade de implementar seus programas preferidos.

b) Até que ponto os candidatos dependem dos líderes dos partidos nacionais para sua nomeação e posição na cédula de votação. A competição intrapartidária é estimulada pelos sistemas de lista aberta, como no Brasil, em que se realizam prévias eleitorais e onde os eleitores podem votar em candidatos individuais ou em blocos adversários dentro do mesmo partido. Quanto maior a competição intrapartidária, mais os políticos são incentivados a resistir às reformas burocráticas que ameacem sua capacidade de distribuir benefícios ao seu eleitorado. 
c) A probabilidade de que adversários políticos assumam o controle dos empregos públicos e recursos burocráticos. De acordo com Geddes, em situações onde haja grande disparidade entre os partidos, os políticos podem concluir que a perda do próprio poder de apadrinhamento pode ser compensada por reformas que neguem este poder a seus adversários. ${ }^{19}$

O desenho constitucional, finalmente, pode ajudar a estruturar a forma como membros do Executivo e Legislativo vão interagir a respeito da reforma. A disciplina partidária tende a ser mais forte em sistemas parlamentaristas, porque a capacidade de dissolver o Legislativo representa para o Executivo e partidos políticos uma grande fonte de poder sobre a base parlamentar (rank and file legislative). Em sistemas presidencialistas, os mandatos legislativos independentes enfraquecem a tendência dos legisladores de apoiar os líderes do Executivo, caso suas iniciativas sejam conflitantes com os interesses distributivos de seus eleitorados.

Terry Moe afirma que os sistemas presidencialistas também afetam a confiança dos legisladores nas restrições legislativas formais de controle do comportamento burocrático. Visto que o sistema de pesos e contrapesos (checks and balances) torna as leis difíceis de serem revertidas, os políticos buscam proteger seus interesses, envolvendo agências burocráticas em "restrições detalhadas, formalmente intrínsecas à legislação". ${ }^{20}$ Nos sistemas parlamentaristas, a fusão dos poderes legislativo e executivo indiscutivelmente facilita às novas maiorias políticas a mudança na legislação vigente. Conseqüientemente, o incentivo à imposição de restrições formais é relativamente fraco, e tanto políticos e burocratas quanto partidos políticos tendem a confiar na reputação e na consulta para comprometer-se com os interesses de suas bases eleitorais. Da mesma maneira, sugere Moe, os sistemas parlamentaristas tendem a ter agências burocráticas melhor preparadas para desempenhar as tarefas que se esperam delas. ${ }^{21}$

Os esforços para examinar essas hipóteses continuam empiricamente tímidos, mas oferecem-nos pontos importantes para o exame de várias fraquezas características das burocracias do serviço público. A ânsia por influência política, por exemplo, ajuda a explicar por que políticos têm geralmente respondido às crises fiscais com cortes generalizados nos salários dos servidores públicos, ao invés de dar prioridade a programas e reduzir a contratação de servidores. No Brasil — um verdadeiro exemplo de partidos fracos e instáveis - o emprego público teve um crescimento real de $65 \%$ durante os anos 80 , com uma grande concentração de contratações feitas por apadrinhamento político no nível municipal. ${ }^{22}$ Essas informações impressionantes sugerem a existência de um padrão similar em alguns países da Europa Oriental, apesar da 
falta de dados comparativos. Contratações por apadrinhamento político aumentaram visivelmente na Polônia, por exemplo, logo após a vitória do Partido Camponês em 1993.

As perspectivas do IER também podem contribuir para o entendimento dos dilemas relativos à descentralização administrativa. Chefes de governo e ministros de Estado relutam em entregar o controle discricionário sobre fluxos de recursos e contratações, apesar da sobrecarga administrativa dos altos dirigentes, dos problemas de coordenação interagencial e da manipulação de informação por parte dos oficiais subordinados. Sob determinadas circunstâncias, no entanto, eles poderão tentar enfraquecer seus rivais detentores de poder no nível nacional, por meio da delegação de autoridade a unidades locais de governo. ${ }^{23}$ Este processo pode trazer avanços de eficiência e eqüidade, como também uma maior participação democrática; mas também pode resultar em excessiva autoridade local, sobreposição de jurisdições administrativas e sérios problemas de coordenação fiscal.

Um passo importante na avaliação do poder esclarecedor das perspectivas do IER é verificar se as diferenças dos padrões de organização burocrática entre os vários países, de fato, correspondem às formas de variação dos sistemas representativos e partidários discutidas acima. Tais comparações, infelizmente, são difíceis de ser feitas. Um problema é a escassez de dados sobre a organização do serviço público em cada país. Mais importante ainda, a presença generalizada de sistemas partidários instáveis e clientelistas em ambas as regiões dificulta a observação do comportamento de variáveis independentes. Será útil observar, no entanto, que o serviço público chileno - um dos mais profissionalizados e honestos da América Latina - instalou-se num contexto de disputa democrática entre partidos ideologicamente diferenciados, ao passo que o sistema partidário descentralizado e instável do Brasil apresenta-se como paradigma de impedimento à reforma burocrática. A maioria dos países ex-comunistas ainda estão envolvidos com as burocracias estatais criadas durante os regimes anteriores. Com o passar do tempo, entretanto, as peculiaridades nacionais na evolução dos partidos programáticos podem aprofundar os contrastes entre as burocracias estatais da Europa Central e Oriental. ${ }^{24}$

As comparações entre países da Europa Oriental e América Latina oferecem também importantes oportunidades de estudo dos efeitos dos regimes parlamentaristas e presidencialistas na organização burocrática. O labirinto de regulamentos formais que cerca as burocracias na América Latina parece moldar-se relativamente bem ao que se espera de regimes presidencialistas. No entanto, devido à ausência de arranjos constitucionais alternativos, é difícil acompanhar as relações causais 
por meio de comparações intra-regionais. $\mathrm{O}$ vasto conjunto de sistemas parlamentaristas e semi-presidencialistas da Europa Oriental oferece um escopo ainda mais amplo de variações e abre a possibilidade de frutíferas análises entre regiões.

A abordagem do IER, com sua forte ênfase nos microfundamentos do comportamento político, promete ser um instrumento poderoso para analisar como as instituições eleitorais e representativas negociam as demandas pela reforma estatal. Entre outras coisas, ela ajuda a explicar porque - apesar da globalização dos mercados de comércio e de capital - muitos governos não reformaram suas instituições estatais para promover uma maior competitividade internacional. A esse respeito, ela é complementar de algumas das interpretações oferecidas pela abordagem de economia política.

Mas essa abordagem também tem sérias limitações. Em primeiro lugar, o IER tende a ser mais útil em situações estáveis (repeated-play), nas quais as regras do jogo são claras e onde há um conhecimento relativamente bom das preferências dos outros atores. A utilidade de tais princípios é muito mais questionável, por outro lado, para os governos constitucionais relativamente novos e pouco institucionalizados da Europa Oriental e América Latina.

Dentro do Congresso americano, o primeiro "lar" empírico do IER, é bastante lógico afirmar que as decisões sobre a estrutura e função da burocracia reflitam os cálculos dos políticos que visem eleger-se. As condições são obviamente diferentes em muitos dos países em questão nesse momento. $\mathrm{O}$ debate disseminado sobre temas constitucionais básicos ainda existe na Polônia, Rússia e México. No Brasil e na Argentina, como também em outros países, existe uma incerteza considerável sobre assuntos como federalismo e reeleição presidencial. Colômbia, Venezuela e Peru experimentaram recentemente reformas constitucionais amplas, e as leis eleitorais estão sujeitas a contestação em quase toda a parte.

Mesmo nesses países, as leis vigentes estão longe de ser consideradas irrelevantes para as escolhas dos mais importantes atores políticos - como demonstraram claramente escritores como Geddes e Ames, no caso do Brasil. Se comparados aos membros do Congresso americano, no entanto, os atores de muitos locais na América Latina e Europa Oriental devem decidir com base em informações limitadas e em curtos horizontes de tempo. Em situações como estas, curiosamente, outro tipo de abordagem da escolha racional - a teoria dos jogos — pode ser mais útil que a versão institucionalista na previsão dos resultados. Mas, em situações de política, comparativamente, pouco institucionalizada, muitos dos atores tendem a buscar metas distintas daquelas do poder político - enriquecimento pessoal ou divulgação de uma posição ideológica, por exemplo. ${ }^{25}$ 
E aqui há uma grande chance de que suas decisões relativas à reforma burocrática sejam produto de um cálculo incorreto.

Outra aparente limitação das perspectivas do IER é o fato de elas serem, em alguns aspectos, melhor preparadas para identificar impedimentos da reforma burocrática do que para explicar por que as mudanças ocorrem. Os políticos podem, por garantia, buscar mudanças institucionais, caso seja de seu interesse fazê-lo; um eleitorado com fortes preferências pela mudança pode incentivar empresários políticos a incorrerem nos custos de superar as barreiras da ação coletiva. Porém, uma das premissas básicas da perspectiva da escolha racional é que as organizações burocráticas existentes refletem as preferências de políticos poderosos que se beneficiam do controle sobre contratações e financiamentos. ${ }^{26}$ Assim, o impulso inicial da reforma tende a vir das demandas que emanam da sociedade ou do sistema internacional, ao invés de virem de dentro do próprio Estado.

Normalmente, analistas que utilizam a perspectiva IER reconhecem que choques externos e demandas sociais são "pontos de partida" para análises da reforma política; eles julgam que as preferências políticas e dificuldades institucionais irão mediar as respostas a tais demandas. ${ }^{27}$ Tratar dessas demandas como "dadas", no entanto, significa que os principais impulsos pela reforma mantêm-se exógenos à estrutura teórica. Isto levanta questões cruciais sobre as condições nas quais grupos sociais mobilizam-se para exigir transformações institucionais, sua força vis-àvis os interesses contrários e sua capacidade de afetar o resultado geral do processo de reforma.

Além disso, até que ponto os políticos intermedeiam tais resultados é um fato que não foi, de qualquer forma, inteiramente demonstrado de modo empírico - um ponto que alguns teóricos adeptos da escolha racional reconheceriam prontamente. Na América Latina, observou Scott Mainwaring, as demandas pela reforma burocrática vieram de vários movimentos sociais e ONGs. As pressões pela descentralização política têm sido especialmente importantes, e têm contribuído para provocar profundas mudanças legais e constitucionais em uma grande variedade de países, incluindo Colômbia, Brasil, Venezuela, Bolívia, México e Argentina. ${ }^{28}$

Além do mais, políticos e legislativos não são os únicos canais pelos quais as demandas pela reforma podem ser implementadas. Nos Estados Unidos, os tribunais têm exercido um papel vital no reordenamento de instituições governamentais, confiando em interesses institucionais e padrões profissionais tipicamente diferentes daqueles dos políticos. $\mathrm{Na}$ América Latina e Europa Oriental, o Poder Judiciário é muito mais fraco, mas poderia, em algum momento, tornar-se uma arena importante para contestar o escopo e a autoridade das agências do Executivo. No Brasil, 
onde os juízes têm sido selecionados por meio de rigorosos concursos e

mantêm, em geral, altos padrões profissionais, movimentos populares e reformadores sociais já começaram a apelar às Cortes, pressionando pela implementação de políticas de bem-estar social e das correspondentes mudanças na prática administrativa. ${ }^{29}$

Finalmente, a capacidade dos políticos e de outros grupos de influenciar a reforma burocrática também é dificultada por legados históricos. As burocracias estatais da América Latina e Europa Oriental não foram criadas de novo por políticos da atualidade; elas foram moldadas fundamentalmente pelos regimes anteriores. Políticos em países ex-socialistas devem lidar com constelações de interesses organizadas inicialmente em torno da nomenclatura e do comando econômicos. David Stark e Laszlo Bruszt mostraram, por exemplo, de que modo as decisões sobre privatização foram dificultadas pelos tipos de redes empresariais que surgiram durante o período comunista. ${ }^{30}$

Na América Latina, os políticos contemporâneos têm de enfrentar os legados burocráticos das negociações políticas do passado, realizadas tanto por regimes autoritários quanto democráticos. Os centros de poder apoiados por pensionistas, sindicatos de servidores públicos ou grupos industriais mostraram-se muito difíceis de mudar na maioria dos países. A reforma estatal na Argentina, Brasil ou Chile não pode ser analisada sem que sejam cuidadosamente considerados os legados de Perón, Vargas ou Pinochet.

\section{Sociologia institucional}

A sociologia institucional engloba uma vasta gama de modos de análise específicos, e por vezes opostos. Três grandes pontos, entretanto, tendem a diferenciar essa abordagem das perspectivas discutidas acima. O primeiro é o fato que as instituições sociais moldam as cognições e valores dos indivíduos que nelas trabalham. Para ambas perspectivas, a da economia política e a da escolha racional, as instituições são sistemas de regras que controlam o modo como os atores buscam atingir metas exógenas — renda, poder político, etc. Na sociologia institucional, o comportamento humano está "inserido" na matriz de organizações e relações informais que fornecem os filtros fundamentais, através dos quais a realidade é interpretada e as identidades básicas e preferências são criadas.

Os cálculos de meios e fins são o embasamento microteórico das duas primeiras perspectivas; na sociologia institucional, ao contrário, o cálculo da racionalidade baseia-se em hábito, imitação, aversão ao risco subjetivamente definido, etc. Hall e Thorp resumiram de forma muito útil 
uma implicação-chave para o entendimento da reforma estatal: "O panorama de instituições existentes atuais," escrevem eles, "fornece um conjunto delimitado de modelos, nos quais aqueles que buscam instituições novas ou melhores vão inspirar-se". ${ }^{31}$

Uma segunda característica — aceita, porém, em menor escala que a primeira - é o peso atribuído à sociedade doméstica e a estruturas historicamente determinadas e institucionalmente distintas, que persistiram apesar das mudanças do sistema internacional. Organizações sociais podem buscar legitimidade e status através da adoção das práticas e características organizacionais de seus adversários globais mais influentes. Essa possibilidade é fortemente sugerida pela hipótese inspiradora de "isomorfismo" de Dimaggio e Powell, por exemplo, e pode ajudar a explicar as tendências contemporâneas internacionais pela independência do Banco Central. ${ }^{32}$ Como enfatizam Dimaggio e Powell, no entanto, as mudanças organizacionais que visam aumentar poder ou status devem ser consideradas insuficientes dentro da perspectiva de aumento da competitividade internacional.

Mais importante ainda, muitos dos que trabalham na linha da sociologia institucional são céticos em relação às teorias de convergência internacional, e enfatizam o caráter dependente das transformações sociais e políticas ocorridas nas sociedades nacionais individuais e em regiões subnacionais. O tema surge de forma recorrente, por exemplo, no trabalho de Stark e Bruszt sobre as mudanças na Europa Oriental. Apesar do colapso do controle das economias, afirmam os dois, os recursos políticos que nasceram no contexto da antiga estrutura apóiam a formação de blocos para a construção da nova ordem. É importante, assim, observar como novos elementos combinam-se com suas "adaptações, arranjos, permutas e reconfigurações das formas institucionais já existentes". ${ }^{33}$

Finalmente, escritores da tradição sociológica institucional costumam desafiar a utilidade das distinções dicotômicas entre "Estado" e "mercado", que caracterizam as perspectivas do IEP e IER. Sociólogos institucionais inclinam-se a fixar sua atenção aos espaços associativos existentes entre a autoridade do Estado e as relações de troca do mercado. Redes informais, associações formais e outros grupos cívicos que preencham tais espaços fornecem os mecanismos críticos de coordenação e alocação de recursos nas sociedades. A longo prazo, sugerem eles, tornar o governo eficaz e accountable dependerá tanto da força da "sociedade civil" quanto da estrutura das próprias instituições públicas. ${ }^{34}$

A capacidade estatal de fomentar o desenvolvimento e implementar serviços sociais é certamente enriquecida pelas ligações com densas constelações que conformam a base das redes e associações privadas. Tais associações fornecem às autoridades públicas informação e apoio político. Elas também influenciam diretamente a qualidade dos serviços públicos, agindo 
como vigilantes e monitores do desempenho governamental. Finalmente, associações cívicas também podem contribuir indiretamente, como sugeriu Robert Putnam, ao encorajarem normas de reciprocidade e confiança mútua, essenciais à colaboração com os setores público e privado. ${ }^{35}$

A importância dessas ligações com a esfera econômica foi explorada nos países capitalistas avançados, em um trabalho editado por Hollingsworth, Streeten e Schmitter, e é o tema central da importante pesquisa de Peter Evans sobre a "autonomia inserida" dos estados em desenvolvimento da Ásia Oriental. ${ }^{36}$ Evans está particularmente atento ao modo como as ligações com tais associações capacita as autoridades do estado em obter informações e cooperação com setores de negócios. Hollingsworth et al oferece uma hipótese ligeiramente distinta, mas complementar: a de que redes e associações podem assumir as funções de coordenação, de modo a reduzir a "carga" das autoridades estatais e a superar as incertezas que, de outro modo, seriam inerentes aos mercados voláteis e imprevisíveis.

Na América Latina e Europa Oriental, a utilidade da dicotomia Estado-Mercado foi também crescentemente desafiada, principalmente após o big-bang das reformas macroeconômicas da década de 80 e do início dos anos 90. A capacidade de resposta aos novos desafios, tais como o crescimento do capital e dos mercados de trabalho, aumento da poupança interna e promoção das exportações, pode depender de como as redes e associações conduzem as relações entre governos e empresas. Esta é a premissa central sobre a qual baseia-se o trabalho de Stark e Bruszt sobre a reforma da propriedade na Europa Oriental, e uma recente pesquisa sobre as relações Estado-empresa na América Latina.

O trabalho de Eduardo Silva sobre o Chile de Pinochet ilustra de modo útil essa perspectiva para a América Latina. ${ }^{37}$ Ele contrasta o isolamento das autoridades estatais durante os anos 70 com o desenvolvimento de formas mais sistemáticas de consulta com o setor privado durante os anos 80. Estas incluem o estabelecimento de relações mais próximas com associações empresariais de ponta, a inclusão de representantes do setor privado em comitês de elaboração de políticas e a incorporação direta dos líderes empresariais em altas posições nos gabinetes. Tais arranjos, segundo Silva, respondem pela recuperação bem-sucedida da crise econômica de 1982/1983. ${ }^{38}$

O ceticismo sobre a dicotomia Estado-mercado encontrado no mencionado trabalho tem um componente claramente normativo e outro analítico. Escritores como Evans, Silva e Stark e Bruszt tendem a duvidar que os cifrões sejam incentivo suficiente para uma atividade econômica eficiente - ou que os governos tenham, uniformemente, a informação necessária para corrigir os fracassos do mercado. Estados e mercados são ambos importantes para a coordenação da atividade social, mas eles funcionam melhor, de acordo com este argumento, quando suas raízes 
vêm de redes e associações que amortecem os riscos e criam um clima de confiança entre os relevantes atores econômicos.

Essa ênfase na confiança e na negociação das metas comuns entre o Estado e atores sociais também oferece uma base para entendermos a evolução da capacidade do Estado em fornecer serviços sociais. Evans refere-se brevemente a este ponto em sua discussão do estado indiano de Kerala, onde os cidadãos construíram um histórico longo de ativismo social para organizar um cuidadoso acompanhamento das clínicas de saúde e do sistema educacional. Como conseqüência, Kerala tem níveis relativamente altos em relação à maioria das medidas de saúde pública, expectativa de vida e alfabetização, mesmo contando com níveis baixíssimos de renda per capita. ${ }^{39}$

Robert Putnam chegou a uma conclusão muito similar ao comparar, de forma muito mais empírica e teórica, os governos regionais na Itália um trabalho com um título bastante apropriado - Making democracy work (Fazendo a democracia funcionar). A análise de Putnam é construída com base na confiança e nas expectativas de reciprocidade que nasceram da participação em associações cívicas. Tais expectativas constituíram uma forma de "capital social" que facilita a cooperação tanto na vida política quanto na econômica. A cooperação bem-sucedida, defende Putnam, faz crescer as expectativas de sucesso futuro; assim, ao contrário de outras formas de capital, o estoque de capital social cresce à medida que é utilizado. ${ }^{40}$

Os escritos de Putnam, junto com os de vários outros autores mencionados na presente seção, não são necessariamente inconsistentes com os argumentos que enfatizam as instituições econômicas e políticas, mas apresentam uma ótica nova e significativa sobre as explicações das capacidades estatais. Enquanto reconhece a importância do desenho institucional, a mensagem principal de Putnam refere-se à força da sociedade civil. Assim, na Itália, a descentralização política aumentou as oportunidades de participação local e contribuiu para a redução da polarização ideológica. Mas outros governos regionais, com estruturas e mandatos legais virtualmente idênticos, comportaram-se de modo bastante diverso, conforme a densidade da vida associativa em suas respectivas regiões.

No nível mais fundamental, a ênfase na estrutura e densidade da vida associativa pode ser particularmente relevante para a capacidade dos estados de garantir a lei e a ordem. Em muitas partes da Europa Oriental e América Latina, os círculos viciosos de corrupção oficial e desconfiança dos cidadãos alcançaram as proporções de uma crise. Em ambas regiões, a crise econômica e o desvio das tentativas de ajuste levaram ao surgimento de uma criminalidade violenta e à crescente privatização da função policial na maioria dos bairros ricos. Máfias de 
drogas tornaram-se profundamente entrincheiradas nos países andinos, no México e em algumas regiões do Caribe. Judiciários fracos e forças policiais mal treinadas foram vencidos por esses problemas. Mal pagos e mal treinados, os policiais operam, em muitos países, como predadores e não protetores dos direitos dos cidadãos.

Para que tais padrões sejam revertidos, sociedades civis fortes deverão desempenhar um papel de vital importância. Em comunidades onde falta uma forte tradição de associação cívica, os indivíduos vivem isolados e estão consequientemente vulneráveis tanto à ação predatória policial quanto aos riscos de represália pela colaboração com as autoridades públicas. Em sociedades onde a participação na vida cívica encorajou a tradição de assistência mútua e de responsabilidade social, estes riscos diminuem. Cidadãos que "chegam na frente" — seja para colaborar com a polícia ou para exigir accountability - têm mais chances de esperar e receber o apoio de seus vizinhos. Desta forma, associações cívicas fortes e estados fortes caminham juntos.

Neste contexto, é importante notar que as organizações comunitárias e movimentos cívicos brotaram por toda a América Latina, especialmente em bairros urbanos pobres. ${ }^{41}$ As organizações vão desde cooperativas alimentícias e associações para a melhoria do bairro até grupos organizados em função de identidades étnicas, de gênero ou religião. Apesar da pobreza e iniqüidade generalizadas, elas parecem ter-se tornado elementos novos, importantes e irreversíveis da vida social. O impacto a longo prazo destas associações pode continuar desconhecido por décadas, mas se Putnam (e Tocqueville) estão certos, elas deverão mostrar serem condições fundamentais para a modernização política e econômica da América Latina - mesmo, ou talvez especialmente, em países como México, Colômbia, Peru, Brasil e outras sociedades onde a manutenção da lei e da ordem parece bastante problemática.

Por todas estas razões, a sociologia institucional parece relevante para vários problemas básicos de governança, tanto na América Latina quanto na Europa Oriental. No entanto, como abordagem analítica, ela também apresenta certas limitações.

Em primeiro lugar, os fundamentos da sociologia política são vagos. Ao enfatizar a formação de preferências e a organização social, as perspectivas sociológicas oferecem um complemento aos problemas da ação coletiva destacados pelas teorias anteriores. Mas as teorias sociológicas fornecem pouca orientação geral que indique quem são os atores relevantes, ou em que base psicológica suas preferências são formadas. A psicologia cognitiva deveria preencher esta lacuna, conforme sugerem Dimaggio e Powell. ${ }^{42}$ A pesquisa sobre aversão ao risco e processamento de informações, por exemplo, deve ser útil para esclarecer as dúvidas 
sobre a "rigidez" das instituições políticas. Neste ponto, porém, as descobertas da psicologia ainda devem ser incorporadas à literatura organizacional dominante.

Em parte porque as motivações individuais não estão claramente especificadas, as teorias sociológicas atuais também deixam de explicar as origens das redes e dos padrões associativos vigentes, ou as dinâmicas através das quais eles se modificam. Quase todos os escritores concluem, corretamente, que as infra-estruturas institucionais vigentes são produtos de conflitos sociais e negociações anteriores, mas se colocada de forma assim tão vaga, essa premissa torna-se indistinguível da simples descrição histórica, ou apela para argumentos de dependência (path dependent) altamente improváveis. O estudo de Putnam, excelente não fosse esse detalhe, sobre as diferenças regionais na Itália é um bom exemplo desta última afirmação. Ele traça a origem das diferenças regionais associando-as a acontecimentos de oito séculos atrás: a ordem social hierárquica estabelecida no Sul, no regime normando do século XII, e os padrões de organização social comunal que se desenvolveram paralelamente no interior das cidades medievais do Norte. ${ }^{43}$

Um terceiro problema, importante tanto para a análise acadêmica quanto para a política pública, é o fato de que as perspectivas sociológicas institucionais geralmente falham ao especificar ex ante de que modo as variações nos tipos de redes e associações podem afetar as operações do Estado ou da economia. O comportamento no interior das associações e redes pode ser direcionado para o confronto, ou para o benefício financeiro (extraction of rents) ou para formas mais produtivas de colaboração com autoridades políticas e atores econômicos. Quando observamos as instâncias específicas de atividade associativa, como poderemos saber se devemos esperar "bons" ou "maus" resultados?

Putnam enfatiza a distinção entre as associações com estruturas hierárquicas e as outras com relações mais igualitárias entre seus membros. O capital social, afirma ele, é gerado pela cooperação entre iguais, ao passo que laços verticais encorajam a exploração, protelação e a manipulação da informação. Outra abordagem seria a análise dos tipos de relação entre as organizações comunitárias, ao invés da pura e simples densidade das associações estruturadas horizontalmente. Richard Locke afirmou, por exemplo, que quanto mais polarizadas tais redes interassociativas, menos chances elas têm de solucionar problemas de forma cooperativa. Pesquisas empíricas sobre ambas proposições, no entanto, estão ainda num estágio muito inicial. ${ }^{44}$

Em uma análise final, é possível que o impacto da vida associativa dependa menos das propriedades "internas" das associações ou redes que das estruturas burocráticas e instituições políticas dentro das quais elas operam. Isso está implícito na tentativa de Peter Evans explicar por 
que as conexões entre "estados em desenvolvimento" e a sociedade não se degeneram em simples provisão de rendas: a resposta, segundo ele, não está nas formas particulares como eles "se inserem", mas sim na autonomia do Estado.

Seguindo linhas similares, poderíamos especular que várias condições econômicas e institucionais têm um efeito fundamental no papel desempenhado por associações e redes nas operações do Estado. Essas incluiriam:

1) A adoção de um "orçamento apertado" via instituições macroeconômicas fortes, que impusessem uma rígida disciplina fiscal e monetária.

2) A liberação das políticas de comércio e de taxas de câmbio competitivas.

3) As formas de acesso político oferecidas aos grupos comunitários, através da descentralização política e de outras reformas institucionais. Tais fatores, devemos notar, são precisamente aqueles enfatizados pelas perspectivas de IEP e de IER.

\section{Conclusões}

A observação de que há áreas concordantes ou complementares entre as três abordagens não deve obscurecer as importantes diferenças de ênfase e pressupostos. As abordagens de sociologia política, particularmente, situam-se bem distantes das outras duas. Os pontos básicos de divergência referem-se à importância dada ao comportamento social determinado e às funções "públicas" das redes e associações; tais argumentos opõem-se diretamente aos pressupostos de racionalidade e às grandes distinções Estado-sociedade encontradas no cerne das IEP e das abordagens de escolha racional.

As diferenças sobre as dinâmicas da reforma do Estado são um pouco menos marcantes. Elas giram basicamente em torno da hipótese de que as instituições estatais chegarão a uma convergência em resposta à globalização econômica e ao empresariado político. As teorias sociológicas nem sempre regulam a possibilidade de convergência entre nações, mas enfatizam muito a "rigidez" das instituições sociais vigentes e as dificuldades impostas pelo legado das lutas e mudanças sociais anteriores. Por esta razão, elas costumam rejeitar, mais rapidamente que os teóricos da IEP ou da escolha racional, as hipóteses de convergência, afirmando que as políticas da reforma do Estado seguirão caminhos nacionais distintos.

As abordagens IEP e IER são conjuntos de literatura muito mais complementares, visto que compartilham muitos dos pressupostos sobre motivação individual e comportamento. No entanto, tais abordagens fazem 
apostas teóricas bastante diversas quando se trata dos tipos de atores que deverão influenciar o resultado dos conflitos sobre reforma estatal. Para a IEP, os atores organizados em função dos interesses econômicos são os decisivos. As instituições políticas podem intermediar tais influências mas, no decorrer do tempo, configurações similares de "demandas" econômicas deverão levar a padrões basicamente similares de organização estatal.

Por outro lado, não existe nenhuma razão inerente para que os teóricos da decisão racional aceitem tais argumentos. Segundo sua abordagem, as instituições políticas influenciam tanto o engajamento dos interesses econômicos na ação coletiva quanto os incentivos para que os políticos respondam. Variações na estrutura de tais instituições podem assim levar os "provedores" de bens políticos a responderem de modos muito diferentes das demandas de suas bases econômicas.

Perceber estas diferenças — mesmo que elas sejam somente uma questão de grau — é importante não só para esclarecer os pressupostos teóricos básicos, mas também para aumentar as possibilidades de pesquisa empírica cumulativa. Tal exercício, no entanto, não implica que à medida que a pesquisa prossiga uma abordagem seja mantida e as outras descartadas. Com efeito, dada a alta complexidade social dos processos que compõem a reforma estatal, é muito provável que cada uma das perspectivas aqui discutidas aporte importantes contribuições. Assim, a questão levantada pela discussão anterior sobre cada perspectiva não é "qual irá explicar mais?”, mas sim “em que domínios de pesquisa cada uma poderá ser mais útil?".

Perspectivas do IEP, como indiquei, parecem particularmente relevantes para a reforma de instituições que gerenciam as relações macroeconômicas com mercados internacionais de comércio e capital. A crescente integração desses mercados representou um inegável incentivo aos líderes políticos em administrar políticas monetárias e fiscais por meio das agências centralizadas de elite, isoladas das pressões legislativas e do controle diário do próprio Executivo.

No entanto, dentro de um conjunto, os fatores enfatizados pelas abordagens IEP — globalização, demandas de grupos de interesse, etc - não parecem ter um forte impacto direto sobre a organização das instituições estatais. Isso é mais evidente quando passamos das instituições dedicadas à gestão macroeconômica àquelas responsáveis por uma gama mais ampla de atividades, tais como proteção policial, política industrial, regulação e bem-estar social. As reformas estatais em tais áreas são menos visíveis para o setor financeiro internacional e compreendem maiores demandas por coordenação entre agências governamentais, como também maior cooperação com grupos da sociedade civil. Os mercados econômicos internacionais, por sua vez, têm pouca chance de impor limites rígidos às reformas realizadas em tais áreas. 
Onde o IEP parece importante — aliás, indispensável — é na análise da determinação da agenda de reforma, adotada atualmente pela maioria dos países do mundo em desenvolvimento. Sociedades diferentes podem lidar com tais agendas de modo bastante distinto, mas a maior parte dos temas em questão - reforma do Banco Central, descentralização e a imagem geral de uma organização estatal "enxuta e mais eficiente" - foi trazida à tona pela crise econômica e pela crescente competição global. A este respeito, o papel desempenhado pelas tendências contemporâneas de competição econômica internacional pode ser análogo àquele desempenhado em séculos anteriores pelas disputas militares internacionais: o de incentivar os dirigentes a realizarem novos acordos com suas bases eleitorais.

Tanto a teoria da escolha racional quanto a sociologia institucional fornecem-nos ferramentas importantes para entendermos como os atores domésticos respondem a tais incentivos. Como discutimos anteriormente, a expansão das instituições eleitorais significa que os membros da "classe política" estão em posição de interferir de forma crucial no processo de reforma, especialmente com respeito à organização do aparato estatal. Isto incluiria questões como contratação de pessoal, mandatos legais e a alocação da autoridade e dos recursos fiscais dentro da burocracia governamental.

A institucionalização da decisão racional pode ser mais útil para entendermos como temas relativos a essas reformas "intra-estatais" são solucionados. Embora o Judiciário possa tornar-se cada vez mais importante, o Poder Legislativo e outras instituições eleitas "processam" a maior parte dos assuntos da reorganização burocrática de uma forma ou de outra. E enquanto os políticos que atuam dentro dessas instituições dependam do apoio das amplas bases sociais, será equivocado concluir que eles não protegerão seus próprios interesses com considerável independência.

Finalmente, as abordagens sociológicas são importantes para entendermos como as organizações estatais "inserem-se" nas estruturas sociais maiores, e como esta "inserção" afeta a capacidade das autoridades públicas de oferecer bens coletivos. As abordagens do IEP e do IER também tratam tais problemas, examinando as relações travadas nas fronteiras entre Estado e sociedade. É somente na sociologia política, no entanto, que encontramos um exame sistemático do entendimento cognitivo e das ligações normativas que embasam tais relações e possibilitam a consolidação de um equilíbrio social estável. A atenção a estas ligações nãoracionais torna a sociologia política um complemento essencial às outras abordagens. Ela é particularmente apropriada para a compreensão dos limites e significados do Estado, a transferência e gestão dos fluxos de informação e das formas de colaboração que se desenvolvem entre as autoridades estatais e os atores oriundos do setor privado. 
1 Guillermo O'Donnel, "On the State, Democratization and Some Conceptual Problems: A Latin American View with Glances at some Postcommunist Countries", World Development 21, 8 (Agosto 1993), 1355-1371.

2 Acadêmicos de várias linhas intelectuais convergem em torno deste ponto: ver Charles Tilly, Coercion, Capital and European States, AD 990-1992 (Cambridge, Mass and Oxford UK: Blackwell, 1992); Theda Skocpol, States and Social Revolutions, (Cambridge: Cambridge University Press, 1979); Douglass C. North, Structure and Change in Economic History (New York, London: W.W. Norton \& Company, 1981); Perry Anderson Lineages of the Absolutist State (New Left Books, 1974). Para uma discussão recente e crítica da extensão de tais argumentos sobre a América Latina, ver Miguel Angel Centeno, "Blood and Debt: War and Taxation in 19th Century Latin America" (December 1996, a ser publicada no American Journal of Sociology).

3 Ver, por exemplo, Peter Hall e Rosemary Thorp, "The New Institutionalism”, documento apresentado na reunião anual da American Political Science Association, setembro 1994.

4 Jeffry A. Frieden e Ronald Rogowski, "The Impact of the International Economy on National Politics: An Analytical Overview”, (manuscrito, setembro 1994).

5 Sylvia Maxfield, Gatekeepers of Growth: The International Political Economy of Central Banking in Developing Countries (manuscrito, julho 1995: a ser publicado pela Princeton University Press).

6 Para declarações úteis sobre esta posição, ver: Peter A. Gourevitch, Politics in Hard Times, (Ithaca: Cornell University Press, 1986); Ronald Rogowski, Commerce and Coalitions (Ithaca: Cornell University Press, 1990).

7 Sylvia Maxfield. Gatekeepers of Growth: The International Political Economy of Central Banking in Developing Countries (julho 1995), p. 24.

8 William Roberts Clark, "Party Structure, Regime Stability and the Governmental Supply of Central Bank Independence", apresentado na reunião anual da American Political Science Association, setembro 1-4, 1994); Adam S. Posen, "Why Central Bank Independence Does Not Cause Low Inflation: There is no Institutional fix for Politics", em R.O. O'Brien, ed. Finance and the International Economy, 7, Oxford University Press, 1993).

9 O termo mais apropriado para o caso chileno é "desconcentração": maior delegação de autoridade a oficiais locais dentro do estado central.

${ }^{10}$ Fernando Rojas, comunicação pessoal, março 1996.

${ }^{11}$ Christine I. Wallich, "Fiscal Decentralization: Intergovernmental Relations in Russia", (The World Bank: Washington, D.C.: Studies of Economics in Transition, Paper nr. 6, 1992; Alexander Neuber, "Fiscal Federalism of Fiscal Separatism: A Second Look at the Russian Federation in 1992 / 1993", (EBRD: London, June 1994).

12 Margaret Levi, Of Rule and Revenue, (Berkeley and Los Angeles: University of California Press, 1988).

13 Alex Cukierman, Steven B.Webb e Bilin Neyapti, "Measuring the Independence of Central Banks and its Effects on Policy Outcomes" The World Bank Economic Review 6,1: (1992) 353-398.

14 Para um estudo comparativo recente sobre a importância dos controles fiscais centralizados, ver Albert Alesina, Ricad Hausmann, Rudolf Hommes e Ernesto Stein, "Budget Institutions and Fiscal Performance in Latin America", (IDB: setembro, 1995). 
15 Ver G.J. Miller e T.M. Moe, "Bureaucrats, Legislators and the Size of Government". American Political Science Review Vol. 77, 1983, pp. 297-323; Barry A. Weingast, "A Rational Choice Perspective on Congressional Norms", American Journal of Political Science, v. 24, 1979, p. 245-263. Morris P. Fiorina, Representatives, Roll Calls and Constituencies (Boston: Lexington Books, 1974); Kenneth A. Shepsle, "Institutional Arrangements and Equilibrium in Multidimensional Voting Models", American Journal of Political Science 1979, v. 23, 27-59.

16 Barbara Geddes, The Politicians' Dilemma (Berkeley: University of California Press, 1994).

17 Barbara Geddes, The Politicians' Dilemma, p. 133, 154.

18 Os parágrafos seguintes referem-se extensivamente ao trabalho de Stephan Haggard, "The Reform of the Bank in Latin America", não publicado, 1995.

19 Geddes, The Politicians' Dilemma.

20 Terry M. Moe, "Political Institutions: The Neglected Side of the Story", Journal of Law, Economics and Organization, v. 6, Edição Especial, 1990, p. 240.

21 Terry M. Moe, "Political Institutions: The Neglected Side of the Story", Journal of Law, Economics and Organization, v. 6, Edição Especial, 1990, p. 242.

22 Helio Zylberstajn, "Pay and Employment issues in the Brazilian Civil Service", em Chaudhry et al., eds., Civil Service Reform in Latin America, p. 128.

${ }^{23}$ As reformas descentralizadoras realizadas na Venezuela no início dos anos 90 são um exemplo de tais processos, como foram os esforços da administração de Salinas, no México, para desconcentrar a prestação de serviços sociais através do Programa Nacional de Solidariedade. Em condições muito mais autocráticas, a tentativa de estabelecer novas alianças nos níveis regional e local foi também um elemento importante na estratégia de líderes reformistas na China e União Soviética. Ver Susan L. Shirk, The Political Logic of Economic Reform in China (Los Angeles: University of California Press, 1993) e Philip G. Roeder, Red Sunset: The Failure of Soviet Politics (Princeton: Princeton University Press, 1993).

${ }^{24}$ Herbert Kitschelt, "The Formation of Party Systems in East Central Europe”, Politics and Society 20, 1, 1992.

${ }^{25}$ Entrevistas conduzidas por Barry Ames, por exemplo, mostram que um alto percentual de legisladores brasileiros ingressa na política buscando construir carreiras de negócios em seus distritos, e não estão interessados em continuar na legislatura por mais de um ou dois mandatos.

${ }^{26}$ Para uma extensa elaboração desse ponto fora das nossas duas regiões, ver Mark Ramseyer e Frances Rosenbluth, Japan's Political Marketplace (Cambridge: Harvard University Press, 1994).

27 Ver Mathew Soberg Shugart e Daniel L. Nielson, "A Liberal Dose: Electoral Reform and Economic Adjustment in the Wake of Crisis", apresentado na reunião anual da American Political Science Association, New York, September 1994.

28 Scott Mainwaring, Review of Politician's Dilemma: Building State Capacity in Latin America, de Barbara Geddes. American Political Science Review, v. 88, n. 4, december 1994, p. 1026.

29 James Holston, "Judicial Reform, Alternative Law and Social Conflict in Democratizing Brazil", (Departamento de Antropologia, Universidade da Califórnia, San Diego, 1996)

30 David Stark, "Path Dependence and Privatization Strategies in East Central Europe", East European Politics and Societies 6,1 (Winter 1992); David Stark e Lazslo Bruszt, "Network Properties of Assets and Liabilities: Patterns of Inter-Enterprise Ownership in the Postsocialist Transformation", apresentado no workshop "Dynamics of Industrial Transformation: East Central European and Asian Comparisons", Budapest University of Economic Science, maio 1995. 
31 Peter Hall e Rosemary Thorpe, p. 20.

32 Paul J. Dimaggio e Walter W.Powell, "The Iron Cage Revisited; Institutional Isomorphism and Collective Rationality", American Sociological Review 48 (Abril): 147-160; novamente publicado em The New Institutionalism in Organizational Analysis, editado por Walter W. Powell e Paul J. Dimaggio. (Chicago e Londres: The University of Chicago Press, 1991). As "comunidades epistêmicas" de profissionais e dirigentes de bancos centrais forneceriam o mecanismo conceitual principal pelo qual sua influência era exercida, Peter M. Haas, "Introduction: Epistemic Communities and International Policy Coordination", International Organization 46,1, inverno, 1992).

33 David Stark, "Path Dependence and Privatization Strategies in East Central Europe", East European Politics and Societies 6,1 (Inverno, 1992), p. 22.

34 Ver, por exemplo, J. Rogers Hollingsworth, Philippe C. Schmitter e Wolfgang Streeck, eds., Governing Capitalist Economies: Performance and Control of Economic Sectors (New York e Oxford: Oxford University Press, 1994). Esp. J.Rogers Hollingsworth e Wolfgang Streeck, "Countries and Sectors: Concluding Remarks on Performance, Convergence and Competitiveness". p. 270-301.

35 Robert D. Putnam, Making Democracy Work: Civic Traditions in Modern Italy (Princeton, New Jersey: Princeton University Press, 1993).

36 Hollingsworth, Streek and Schmitter, op.cit.; Peter Evans, Embedded Autonomy: States and Industrial Transformation, (Princeton, New Jersey: Princeton University Press, 1995).

37 Eduardo Silva, "Capitalist Coalitions, the State and Neoliberal Economic Restructuring: Chile 1973-1988”. World Politics 45 (1993); Ben Ross Schneider e Sylvia Maxfield, "Business, the State and Economic Performance in Developing Countries", em Maxfield e Schneider, eds. Business and the State in Developing Countries (a ser publicado 38 Ibid. pela Cornell University Press. 1997).

39 Evans, Embedded Autonomy. p. 235-240.

40 Putnam, Making Democracy Work.

41 Para uma interessante discussão dos novos tipos de "redes associativas" na América Latina, ver Douglas A. Chalmers, Scott B. Martin, Kerianne Piester, "Associative Networks: A New Structure of Representation for the Popular Sector?" In: The New Politics of Inequality in Latin America, editado por Douglas A. Chalmers et al. (Oxford University Press 1996).

42 Walter W. Powell and Paul J. Dimaggio, "Introduction," In: The New Institutionalism in Organizational Analysis.

43 Putnam, Making Democracy Work, p. 163-187.

44 Richard M. Locke, Remaking the Italian Economy (Ithaca: Cornell University Press, 1994). 


\section{A política da reforma do Estado: um exame de abordagens teóricas Robert R. Kaufman}

$\mathrm{O}$ artigo aborda a contribuição de três diferentes perspectivas teóricas - o institucionalismo da economia política (IEP), o institucionalismo da escolha racional (IER) e o institucionalismo da sociologia (IS) - para a compreensão dos desdobramentos da organização estatal e das políticas de reforma do aparelho do Estado. Tais perspectivas são complementares ou excludentes, mas cada uma oferece explicações diferentes sobre atores, preferências e dificuldades a serem enfrentadas. O texto explica algumas das hipóteses sobre reforma do Estado, contidas em cada perspectiva, observando as suas vantagens e limitações, e fornece também uma avaliação preliminar da relevância teórica de cada uma para a pesquisa empírica na América Latina e Europa Oriental.

\section{La política de la reforma del Estado: un examen de abordajes teóricos Robert R. Kaufman}

El artículo trata de la contribución de tres diferentes perspectivas teóricas - el institucionalismo de la economia política (IEP), el institucionalismo de la opción racional (IER), y el institucionalismo de la sociología (IS) - para la comprensión de los desdoblamientos de la organización estatal y de las políticas de reforma del aparato del Estado. Tales perspectivas son complementares o excluyentes, pero cada cual ofrece explicaciones diferentes sobre actores, preferencias y dificultades a afrontarse. El texto explica algunas de las hipótesis sobre la reforma del Estado, contenidas en cada perspectiva, observando sus ventajas y limitaciones y también provee una evaluación preliminar del relieve teórico de cada cual para la investigación empírica en América Latina y Europa Oriental.

\section{The policy of State reform: a review of theoretical approaches Robert R. Kaufman}

The paper approaches contributions of three different theoretical perspectives - the political economic institutional approach (IPE), the institutional approach of rational choice (IRC) and the sociological institutional approach (IS) - for understanding the branching of the state organisation and the policies for the State apparatus reform. Such perspectives are complementary or excluding, but each of them offers different explanations about authors, preferences and difficulties to be faced. The text explains some of the hypotheses about State reform within each perspective, observing their advantages and shortcomings and also provides a preliminary evaluation of the theoretical relevance of each one for the empirical research in Latin America and Eastern Europe.
Revista do

Serviço

Público

Ano 49

Número 1

Jan-Mar 1998
Professor of political science, Rutgers University, New Brusnwiek, New Jersey — USA.

Traduzido por Christina Ervilha e Vanessa Silveira 
